\title{
Functional capacity vs side effects: treatment attributes to consider when individualising treatment for patients with rheumatoid arthritis
}

\author{
Karin Schölin Bywall ${ }^{1}$ (1) $\cdot$ Bente Appel Esbensen ${ }^{2,3} \cdot$ Marta Lason $^{4} \cdot$ Marie HeidenvalI $^{5} \cdot$ Inger Erlandsson $^{5}$. \\ Jennifer Viberg Johansson ${ }^{1,6}$
}

Received: 16 June 2021 / Revised: 6 October 2021 / Accepted: 7 October 2021 / Published online: 15 October 2021

(C) The Author(s) 2021, corrected publication 2022

\begin{abstract}
Introduction Individualisation of rheumatoid arthritis (RA) treatment needs to take account of individual patients' preferences to increase patient-centeredness in treatment decisions. The aim of this study was to identify patient-relevant treatment attributes to consider when individualising treatment for patients with RA.

Method Patients with RA in Sweden were invited to rank the most important treatment attributes in an online survey (April to May 2020). Semi-structured interviews were conducted (October to November 2020) to further identify and frame potential attributes for shared decision-making. The interviews were audio-recorded, transcribed and analysed using thematic framework analysis. Patient research partners and rheumatologists supported the selection and framing of the treatment attributes across the assessment.

Results The highest ranked attributes $(N=184)$ were improved functional capacity, reduced inflammation, reduced pain and fatigue and the risk of getting a severe side effect. The framework analysis revealed two overarching themes for further exploration: treatment goals and side effects. 'Treatment goals' emerged from functional capacity, revealing two dimensions: physical functional capacity and psychosocial functional capacity. 'Side effects' revealed that mild and severe side effects were the most important to discuss in shared decision-making.

Conclusions Functional capacity (physical and psychosocial) and potential side effects (mild and severe) are important treatment attributes to consider when individualising RA treatment. Future research should assess how patients with RA weigh benefits and risks against each other, in order to increase patient-centeredness early on the treatment trajectory.

\section{Key Points}

- It is essential for the individualisation of treatment to identify what attributes patients with RA are willing to trade off in order to increase patient-centeredness in precision care.

- Individualisation of rheumatoid arthritis treatment needs to account for patients' preferences on functional capacity and side effects.

- Future research is needed to assess how patients with rheumatoid arthritis weigh functional capacity against side effects, in order to increase patient-centeredness in treatment decisions.
\end{abstract}

Keywords Discrete choice experiment $\cdot$ Individualisation of treatment $\cdot$ Patient preferences $\cdot$ Rheumatoid arthritis $\cdot$ Shared decision-making

\section{Introduction}

Finding the best treatment for an individual patient can be challenging, especially in conditions that can be treated with many different medicines. Rheumatoid arthritis (RA) is one such condition: an inflammatory autoimmune disease, usu-

Both Marie Heidenvall and Inger Erlandsson are patient research partners

Karin Schölin Bywall

karin.bywall@crb.uu.se

Extended author information available on the last page of the article ally treated with disease-modifying antirheumatic drugs (DMARDs), which target joint inflammation in various different ways [1]. This creates differences that may affect patients' daily life, for instance, in administration, effectiveness and side effects. The uncertainty around treatment 
response in RA has resulted in a trial-and-error approach to identifying the best treatment. This can be both exhausting to patients and wasteful of healthcare resources. The major weakness of the current treatment approach is the lack of biomarkers for immediate stratification of an individual patient to the most appropriate medicine [2]. Therefore, a more individualised treatment approach called 'precision care' attempts to find biomarkers through 'omics' to match patients with therapies which they are likely to respond to, using prediction algorithms [3].

All available treatment alternatives require trade-offs between potential benefits and risks. The question remains regarding how to identify the best treatment for an individual patient. Therefore, it is essential for individualisation of treatment with DMARDs to identify what attributes patients with RA are willing to trade off, in order to increase patientcenteredness early on the treatment trajectory [4-7]. There is a large body of existing literature on patient preferences for RA treatment from a clinical standpoint [8-10]. Such studies focus mainly on endpoints relating to decreasing the number of tender and swollen joints [2]. However, individualisation of RA treatment may also consider how the treatment impacts a patient's daily life, information that may not be included in prediction algorithms. Potentially, quantitative assessments of patient-relevant benefits and risks may be considered in precision care, to facilitate shared decisionmaking by aligning prediction algorithms with patients' preferences [11-13].

Individualisation of RA treatment needs to account for individual patients' preferences to increase patient-centeredness in treatment decisions. Therefore, the aim of this study was to identify patient-relevant treatment attributes to consider when individualising treatment for patients with RA.

\section{Material and methods}

We used a step-wise approach in the identification and selection of treatment attributes: (1) attribute identification, (2) attribute ranking, (3) semi-structured interviews, and (4) attribute framing.

The attribute and level identification was influenced by the report for the Good Research Practices for Conjoint Analysis Task Force [14]. The identification began with a scoping literature review, followed by attribute filtration and validation discussions with rheumatologists and patient research partners. Nine potential attributes were ranked by patients with RA to further guide identification and selection. Semi-structured interviews were conducted to target and frame the most important attributes and levels. Refinement of the potential attributes and levels was carried out via discussions within the research team and with external rheumatologists.

\section{Attribute identification: step 1}

A total of 373 articles were screened to identify relevant treatment characteristics (attributes) for patients with rheumatoid arthritis through a scoping literature review. Of these articles, 23 articles were eligible for inclusion in attribute identification [1, 6, 8, 9, 15-33]. Attribute selection was based on the relevance to the decision context (i.e. shared decisions in precision medicine for patients with RA) [14].

The scoping literature review revealed that that there was already a large body of existing knowledge on patient preferences from a clinical standpoint. Moreover, a large number of attributes had been assessed in previous research. Therefore, patients were asked to rank these attributes and to narrow down the number of potential attributes.

In this stage, attributes were sorted into categories: administration, treatment effects and side effects (Table 1). Administration included the potential attributes 'route of administration' and 'frequency of administration'. Treatment effects encompassed 'reduction in the number of swollen joints', 'improvement in functional capacity', 'reduced inflammation' and 'pain relief'. Side effects included 'mild short-term side effects', 'long-term side effects' and 'severe side effects'. The potential attributes were discussed with rheumatologists and two patient research partners from the Swedish Rheumatism Association (MH and IE). Nine potential attributes were included in step 2.

\section{Attribute ranking: step 2}

A ranking exercise was chosen as the next step to narrow down the long list of potential attributes. Patients with RA in Sweden were asked to rank nine treatment attributes in an online survey via a mobile application (www.elsa.scien ce.se). Users of the mobile application received an invitation to participate in the ranking exercise in April 2020; the data collection lasted until the end of May 2020. Patients were eligible for the ranking exercise if 18-80 years of age, an established RA diagnosis and able to understand the questions without aid. In total, 262 potential respondents started the survey, of whom $n=184$ were included in the final analysis. Responders were excluded if not providing informed consent before accessing the survey. The survey was approved by the regional ethics review board in Uppsala, Sweden (Reg no. 2020/00556). Data collection and recording, storage and dissemination were governed by the General Data Protection Regulation (GDPR) and Uppsala University's data protection and security policies.

The attributes in the ranking exercise were presented to each respondent in a random order. Respondents ranked all of the attributes, with the most important attribute (i.e. highest ranked) given 9 points and the rest of the attributes 
Table 1 Attribute identification from the scoping literature review

\begin{tabular}{|c|c|c|}
\hline Organised categories & Attribute found in review & Attributes for ranking \\
\hline Administration & $\begin{array}{l}\text { Route of administration } \\
\text { Combination therapy } \\
\text { Medication burden } \\
\text { Frequency of administration } \\
\text { Dose frequency }\end{array}$ & Route of administration \\
\hline \multirow[t]{3}{*}{ Treatment effects } & $\begin{array}{l}\text { Duration of effect } \\
\text { Time to onset of drug effect } \\
\text { Chance of a major symptom improvement } \\
\text { Chance of benefit } \\
\text { Going into remission } \\
\text { Efficacy } \\
\text { Radiographic progression }\end{array}$ & Reduced inflammation \\
\hline & $\begin{array}{l}\text { Improvement in ability to perform daily tasks } \\
\text { Improvement in physical function }\end{array}$ & Improved in functional capacity \\
\hline & $\begin{array}{l}\text { Pain relief } \\
\text { Fatigue }\end{array}$ & Reduced pain and fatigue \\
\hline \multirow[t]{5}{*}{ Side effects } & $\begin{array}{l}\text { Headache } \\
\text { Nausea } \\
\text { Vomiting } \\
\text { Diarrhoea } \\
\text { Injection site reaction } \\
\text { Abnormal laboratory results }\end{array}$ & Risk of mild side effects \\
\hline & $\begin{array}{l}\text { Rash } \\
\text { Oral ulcers } \\
\text { Alopecia } \\
\text { Weight changes } \\
\text { Acne }\end{array}$ & $\begin{array}{l}\text { Risk of side effects leading to } \\
\text { changed appearance }\end{array}$ \\
\hline & $\begin{array}{l}\text { Emotional well-being } \\
\text { Spiritual well-being } \\
\text { Aspects of participation } \\
\text { Independence }\end{array}$ & Risk of psychological side effects \\
\hline & $\begin{array}{l}\text { Pneumonitis } \\
\text { Risk of a serious side effect } \\
\text { Possible rare lung or liver reaction } \\
\text { Major toxicity } \\
\text { Risk of tuberculosis } \\
\text { Cancer } \\
\text { Extremely rare adverse events }\end{array}$ & Risk of severe side effects \\
\hline & $\begin{array}{l}\text { Risk of serious joint damage within } 10 \text { years } \\
\text { Bone erosion }\end{array}$ & Risk of damage in the long term \\
\hline
\end{tabular}

given a decreasing number, down to 1 point. We used the $\chi^{2}$ test to explore if there was any significant differences in patient preferences related to disease duration, age, education or health literacy [34]. Disease duration was dichotomised as under 10 years of RA and over 10 years of RA. The cut-off for age was 45 years. Patient research partners assisted in the development of the semi-structured interview guide, to explore the results of the ranking exercise with the aim of identifying patient-relevant attributes and levels to be assessed in a quantitative patient preference assessment, such as a discrete choice experiment [10].

Health literacy was calculated for each respondent [35]. Individuals responding with strongly disagree or disagree to one of the items were categorised as having inadequate HL. Individuals responding with neither agree nor disagree to one of the items were categorised as having problematic HL. Finally, individuals responding agree or strongly agree to all the items were categorised as having sufficient HL.

\section{Semi-structured interviews: step 3}

Semi-structured interviews were chosen as the next step to get a deeper understanding of the results from the ranking exercise. Respondents in the ranking exercise were asked to participate in semi-structured interviews (October to November 2020) via a mobile application (www.elsa.science.se). Inclusion criteria's for the interviews were 18 years of age, an established RA diagnosis less than 5 years ago and able to understand and answer the interview questions without aid. 
Potential respondents were excluded if they had RA for more than 5 years. The interviews were conducted by KSB, audiorecorded and transcribed. Each interview was scheduled for $1 \mathrm{~h}$. The analysis was performed by the authors KSB, MH, IE, BAE and JVJ. The thematic framework analysis method was chosen for the analysis, as it has the potential to support multiple research teams where not all research team members have experience of qualitative data analysis. This method provides steps to follow and produces structured outputs of summarised data [36]. The framework analysis was initiated by coding meaning units of the transcribed interviews. Each code described some contents of the text. The analytical framework was developed alongside performance and analysis of the interviews. Data saturation was discussed among the coders and concluded after 10 interviews. Codes were grouped into categories under the overarching themes: administration, treatment effects and side effects (Table 1). The framework was applied to and refined for each transcript in a structured manner. Each category was then summarised based on quotes for the codes. These category summaries were considered in the development of potential attributes to consider in shared decision-making. The framework analysis was also discussed with two rheumatologists, to reflect clinical practices.

\section{Attribute and level framing: step 4}

Validation interviews were conducted to test the framing of the attributes and to assign levels to the attributes. An invitation was sent to the respondents by email, with a link to the survey. All respondents provided informed consent. Interviews were conducted digitally with three patients with RA. Some of the attribute framing was adjusted after this. The attribute refinement also included discussions with two rheumatologists and the research team.

\section{Results}

\section{Attribute identification: step 1}

The attribute identification resulted in nine potential attributes relevant for the quantitative patient preference assessment. Three attributes related to treatment effect: 'the treatment's ability to increase my functional capacity to have an active lifestyle','the treatment's ability to reduce inflammation in my joints' and 'the treatment's ability to decrease my pain and fatigue'. Five of the attributes related to potential side effects: 'to avoid mild short-term side effects such as nausea and headache'; 'to avoid damage in the long term such as arteriosclerosis or osteoporosis'; 'to avoid severe side effects such as infections leading to me being hospitalised'; 'to avoid side effects that can affect my mental health, such as mood changes or sleep disturbance'; and 'to avoid side effects that can alter the way I look, such as skin rash or weight change'. Route of administration and frequency of administration were merged into one, to reduce the number of attributes.

\section{Attribute ranking: step 2}

Most of the respondents were female (93.5\%), with a disease duration over 10 years $(66.3 \%)$. The average age span was between 45 and 64 years (56\%). Responders were generally highly educated, with $59.3 \%$ having studied at university (Table 2).

The attribute rankings are summarised as presented in Fig. 1. The most important attribute was 'improved functional capacity', which was given 1,310 points, with the second most important being 'reduced inflammation', given 1,308 points. The third was 'reduced pain and fatigue' ( 1,273 points), followed by 'risk of severe side effects' (1,072 points), long-term side effects ( 895 points), risk of

Table 2 Demographic characteristics

\begin{tabular}{|c|c|c|c|}
\hline Disease duration & & $n=184$ & $\%$ \\
\hline & $0-3$ months & 2 & 1.1 \\
\hline & $3-6$ months & 3 & 1.6 \\
\hline & 6-12 months & 7 & 3.8 \\
\hline & $1-2$ years & 14 & 7.6 \\
\hline & $2-3$ years & 18 & 9.8 \\
\hline & $3-5$ years & 6 & 3.3 \\
\hline & $5-10$ years & 12 & 6.5 \\
\hline & $10+$ years & 122 & 66.3 \\
\hline \multirow[t]{6}{*}{ Age (years) } & $18-24$ & 10 & 5.4 \\
\hline & $25-34$ & 14 & 7.6 \\
\hline & $35-44$ & 22 & 12 \\
\hline & $45-54$ & 50 & 27.2 \\
\hline & $55-64$ & 53 & 28.8 \\
\hline & $65+$ & 35 & 19 \\
\hline \multicolumn{4}{|l|}{ Gender } \\
\hline & Female & 172 & 93.5 \\
\hline & Male & 12 & 6.5 \\
\hline \multicolumn{4}{|l|}{ Education } \\
\hline & Elementary school 9 years & 12 & 6.5 \\
\hline & 2-year high school & 21 & 11.4 \\
\hline & 3-4-year high school & 31 & 16.8 \\
\hline & College & 11 & 6 \\
\hline & University less than 3 years & 36 & 19.6 \\
\hline & University more than 3 years & 73 & 39.7 \\
\hline \multicolumn{4}{|l|}{ Health literacy } \\
\hline & Insufficient & 13 & 7 \\
\hline & Problematic & 74 & 40 \\
\hline & Sufficient & 97 & 53 \\
\hline
\end{tabular}


psychological side effects (836 points), risk of side effects affecting appearance (619 points), risk of mild short-term side effects (547 points) and route of administration (420 points). The $\chi^{2}$ test showed that there was no statistically significant differences in patients' rankings in relation to disease duration, age, education or health literacy. Figure 1 illustrates the attribute rankings and that there were no statistically significant differences when strafing the data on disease duration of RA and age. The bar charts present two dichotomised age categories, $1=18-54$ and $2=55$ and older for each attribute. Each bar chart presents dichotomised disease duration in two colours, bottom $=$ over 10 years of RA and top $=$ under 10 years of RA.

\section{Semi-structured interviews: step 3}

In total, 10 interviews were conducted ( $n=8$ female). Respondents represented several geographic locations in Sweden. The first interview was considered a pilot interview, with the purpose to test the interview guide. The respondents represented people from all age ranges in the ranking exercise. All of the respondents had been diagnosed with RA within the last 5 years and were chosen to represent the views of relatively recently diagnosed patients.

Two overarching themes emerged from the framework analysis: treatment goals and side effects (Table 3). 'Treatment goals' emerged from the main categories 'physical treatment goals' and 'psychosocial treatment goals'. Physical treatment goals emerged from the codes 'inflammation', 'swollen joints', 'pain' and 'physical fatigue'. One of the respondents said: 'The most important thing for me is to function, yeah to be able to work, and do the things I am used to and such'. Psychosocial treatment goals emerged from the codes 'social ability', 'mental ability', 'pain' and 'psychosocial fatigue'. One respondent said: 'I avoided doing things, if you feel bad you don't want to meet people'. The attributes 'improved physical functional capacity' and 'improved psychosocial functional capacity' emerged from patients' individual treatment goals. These attributes included elements of several attributes from the ranking exercise: reduced inflammation, improved functional capacity, reduced pain and fatigue.

The theme 'side effects' emerged from the categories 'transient mild side effects', 'permanent long-term side effects' and 'acute severe side effects'. Each of the categories was framed as a potential attribute in the preference assessment. Examples of mild side effects were nausea or headache (i.e. excluding the sub-categories related to psychological side effects and appearance). One respondent said: 'One of the medicines I took gave me nausea the whole day after'. For the attribute 'likelihood of a severe side effect', the examples used were severe infections or allergic reactions.

\section{Attribute framing: step 4}

Some of the attributes were adjusted to improve the framing. Levels were assigned to the attributes to support the setting of individual treatment goals as part of shared decision-making. The attribute refinement process also included discussions with two rheumatologists and the research team.

Physical functional capacity was framed as 'my ability to perform daily tasks and activities, such as work, studies, household, family and spare time'. Psychosocial functional

Ranking of all attributes

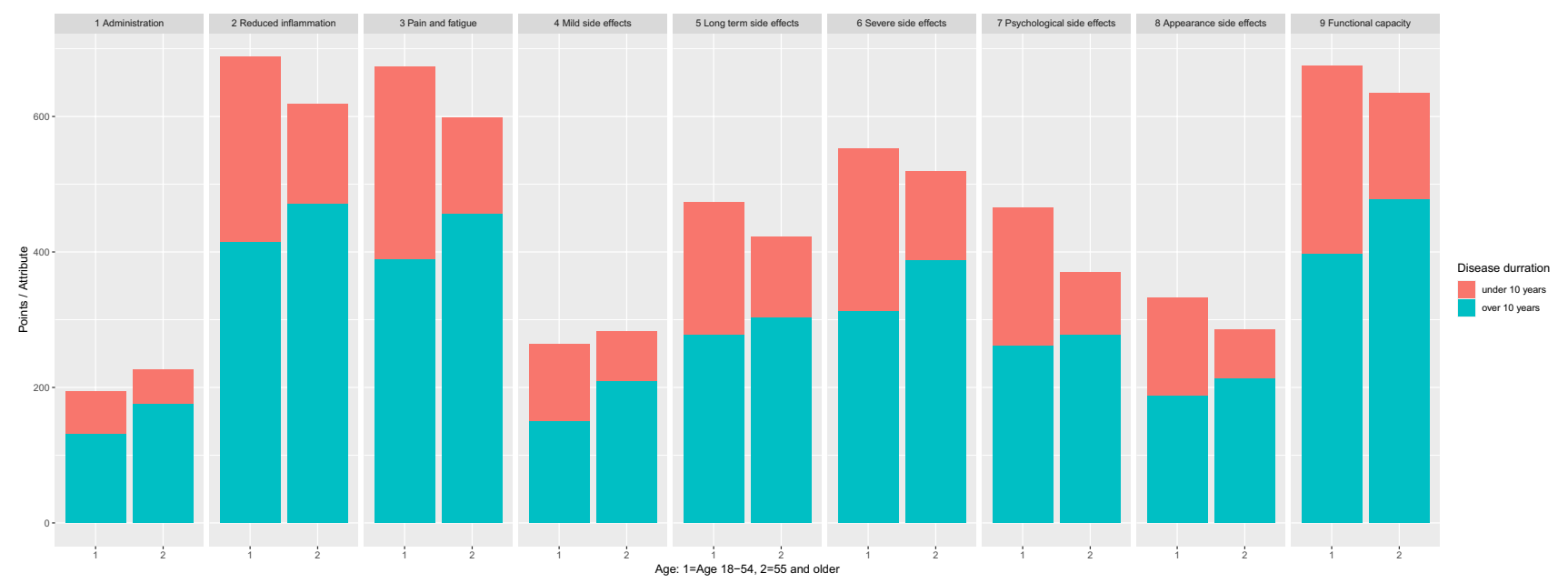

Fig. 1 Attribute ranking stratified on disease duration and age 
Table 3 Framework analysis of semi-structured interviews to identify attributes

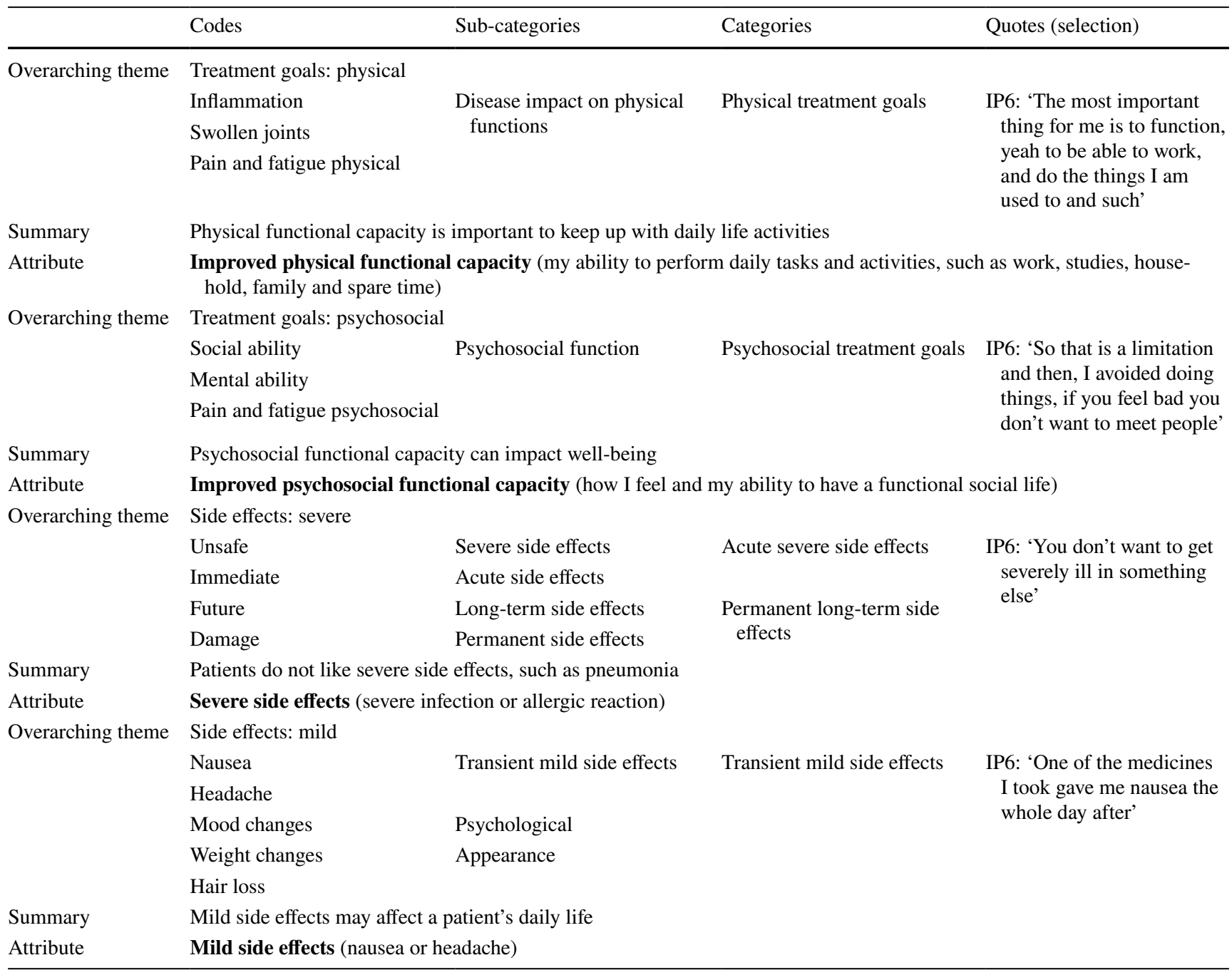

capacity was framed as 'how I feel and my ability to have a functional social life'. Both attributes were assigned the levels 25, 50, 75 and 100 (full function).

The attribute 'mild side effects' was framed as the frequency of getting nausea or headache. Three levels for mild side effects were identified and adjusted after discussion: often (weekly), sometimes (monthly) and rarely (quarterly).

Severe side effects were framed as the likelihood of getting a severe side effect, such as a severe infection or allergic reaction. Three levels were assigned after attribute refinement: common ( 1 in 10 can get the side effect), uncommon ( 1 in 100 can get the side effect) and rare ( 1 in 1,000 can get the side effect) to reflect the information given on the package leaflets for existing DMARDs.

\section{Discussion}

The aim of this study was to identify patient-relevant treatment attributes to consider when individualising treatment for patients with RA. We outlined an explorative approach to identify patient-relevant treatment attributes by using both quantitative ranking and following up the results in semistructured interviews. The reason for taking this approach was the large body of existing knowledge from a clinical standpoint. The attribute ranking generated a first insight into what attributes were most important to patients. We decided to follow these results in further attribute exploration through semi-structured interviews with patients for further exploration. We identified four treatment attributes, with 3-4 levels each, as being relevant for patients with RA in precision care. The attributes were related to functional capacity (physical and psychosocial) and potential side effects. 
Results from the ranking exercise were in line with previous research in the same field regarding preferences among patients with RA [1, 6, 8, 9, 15-33]. However, we decided to exclude attributes related to treatment administration, as the route of administration is seldom the most important attribute in these studies and was ranked lowest in this study. Administration methods may differ between different treatment alternatives, and there may sometimes be a need for tight control in order to find a suitable treatment. The relevance of such practical issues should not be underestimated, as treatment must fit into a patient's daily life. Therefore, there may be a need for clinicians to broach such matters in discussions with patients.

One of the most important treatment attributes seen in the larger literature body was treatment effect [37]. Treatment effect is commonly assessed in terms of 'improvements', 'chance of efficacy' or 'duration of effects' [9]. Treatment effect reflects the attribute 'reduced disease activity' selected in the ranking exercise. Effectiveness was an attribute among treatment goals, in terms of physical and psychosocial functional capacity. Physical functional capacity has previously been addressed in research as the patient's wish for 'a normal life' through symptom relief [38]. Physical functional capacity has previously been assessed as 'improvement in ability to perform daily tasks and activities' [25], and 'psychosocial functional capacity' has been assessed as wellbeing, both physical, mental, emotional and spiritual [28, 30]. Similar attributes for mild side effects have previously been assessed as 'risk of immediate mild treatment reaction' [26], and severe side effects are commonly measured in frequencies of 'potential risks' [29]. The results of this study suggested that attributes serving to support patients in treatment individualisation need to reflect patients' own treatment goals and preferences rather than taking a clinical standpoint. Therefore, shared decision-making in RA treatment should consider attributes that influence a patient's daily life and quality of life, to support patients in individualisation of care.

A strength of this study was that we were able to include a large number of respondents in the ranking exercise. The process was also supported by rheumatologists and patient research partners. However, a limitation of this study may have been that recruitment via a mobile application could exclude certain groups of patients who do not use such applications. Therefore, the results of this study may not be generalisable to the general RA population in Sweden.

Recommendations for precision care should include data from the patient perspective, to support patients in shared decision-making. Methods for assessing and using patient preferences in order to strengthen patients in shared decision-making in precision care are lacking. Quantitative assessments of patient-relevant benefits and risks may support patients in shared decision-making, so treatment decisions can be aligned with their preferences. Future research should assess how patients with RA weigh benefits and risks against each other in order to increase patientcenteredness early on the treatment trajectory.

\section{Conclusions}

This study contributes to a deeper understanding of what is important to patients in treatment individualisation. Treatment attributes important to patients were related to improving functional capacity and acceptable side effects. Quantitative assessments of patient preferences should consider treatment effects on patients' own treatment goals and the impact that treatment has on daily life activities. Future research is needed to support the use of patient preferences in order to strengthen patients in individualisation of care.

Acknowledgements The authors would like to thank the Swedish Rheumatism Association for their support as research partners. We would also like to thank Elsa Science for their support in recruiting respondents to this study. Our sincere gratitude also goes to external members of the research team who have provided input in the selection and framing of the attributes and levels: Johan Askling, Lars Klareskog, Viking Huss, Kristin Waldenlind, Liselotte Tidblad and Viktor Molander.

Author contribution All authors have made substantial contributions to the conceptualisation and design of the work and the analysis and interpretation of data. All authors contributed to drafting of the work and substantively revised it. All authors read and approved the final manuscript.

Funding Open access funding provided by Uppsala University. The financial support for this study was provided from the personalised Medicine in RA by combining genomics and biomarkers and clinical and patient-derived data from the Nordic countries (NORA) project, which has received funding from NordForsk under grant agreement no. 90825 . The funding agreement ensured the authors' independence in designing the study, interpreting the data, writing and publishing the report.

Data availability Data from the current study is available from the corresponding author on reasonable request.

\section{Declarations}

Ethics approval The study was approved by the Ethics Review Authority in Sweden (Dnr 2020-00556). All procedures performed in studies involving human participants were in accordance with the ethical standards of the institutional and/or national research committee and with the 1964 Helsinki Declaration and its later amendments or comparable ethical standards.

Consent to participate Informed consent was obtained from all individual participants included in the study. The authors confirm that all patient/personal identifiers have been removed or disguised, so the patient/person(s) described cannot be identified through the details of the story. 
Consent for publication All authors of the manuscript have read and agreed to its content and are accountable for all aspects of the accuracy and integrity of the manuscript in accordance with the ICMJE criteria.

Conflicts of interests Karin Schölin Bywall and Jennifer Viberg Johansson have no conflict of interest to declare. Bente Appel Esbensen have received speaking fees from Pfizer and Lilly.

Marie Heidenvall and Inger Erlandsson are supported by the Swedish Rheumatism Association as patient research partners. Marta Larson is employed at ELSA Science.

Open Access This article is licensed under a Creative Commons Attribution 4.0 International License, which permits use, sharing, adaptation, distribution and reproduction in any medium or format, as long as you give appropriate credit to the original author(s) and the source, provide a link to the Creative Commons licence, and indicate if changes were made. The images or other third party material in this article are included in the article's Creative Commons licence, unless indicated otherwise in a credit line to the material. If material is not included in the article's Creative Commons licence and your intended use is not permitted by statutory regulation or exceeds the permitted use, you will need to obtain permission directly from the copyright holder. To view a copy of this licence, visit http://creativecommons.org/licenses/by/4.0/.

\section{References}

1. Fraenkel L, Nowell WB, Michel G, Wiedmeyer C (2018) Preference phenotypes to facilitate shared decision-making in rheumatoid arthritis. Ann Rheum Dis 77(5):678-683. https://doi.org/10. 1136/annrheumdis-2017-212407

2. Smolen JS, Landewé RBM, Bijlsma JWJ, Burmester GR, Dougados M, Kerschbaumer A, McInnes IB, Sepriano A, van Vollenhoven RF, de Wit M et al (2020) EULAR recommendations for the management of rheumatoid arthritis with synthetic and biological disease-modifying antirheumatic drugs: 2019 update. Ann Rheum Dis 79(6):685-699. https://doi.org/10.1136/annrh eumdis-2019-216655

3. Aletaha D (2020) Precision medicine and management of rheumatoid arthritis. J Autoimmun 110:102405. https://doi.org/10.1016/j. jaut.2020.102405

4. Ho M, Saha A, McCleary KK, Levitan B, Christopher S, Zandlo K, Braithwaite RS, Hauber AB (2016) A framework for incorporating patient preferences regarding benefits and risks into regulatory assessment of medical technologies. Value Health 19(6):746-750. https://doi.org/10.1016/j.jval.2016.02.019

5. Muhlbacher AC, Juhnke C, Beyer AR, Garner S (2016) Patientfocused benefit-risk analysis to inform regulatory decisions: the European Union Perspective. Value Health 19(6):734-740. https:// doi.org/10.1016/j.jval.2016.04.006

6. Nolla JM, Rodriguez M, Martin-Mola E, Raya E, Ibero I, Nocea G, Aragon B, Lizan L, Prades M (2016) Patients' and rheumatologists' preferences for the attributes of biological agents used in the treatment of rheumatic diseases in Spain. Patient Prefer Adherence 10:1101-1113. https://doi.org/10.2147/PPA.S106311

7. Bywall KS, Veldwijk J, Hansson MG, Kihlbom U (2019) Patient perspectives on the value of patient preference information in regulatory decision making: a qualitative study in swedish patients with rheumatoid arthritis. Patient 12(3):297-305. https://doi.org/ 10.1007/s40271-018-0344-2

8. Hsiao B, Binder-Finnema P, Benjamin Nowell W, Michel G, Wiedmeyer C, Fraenkel L (2019) Preference phenotypes can be used to support shared decision-making at point-of-care for patients with rheumatoid arthritis: a proof of concept study. Arthritis Care Res 71(5):629-637. https://doi.org/10.1002/acr. 23684

9. Durand C, Eldoma M, Marshall DA, Bansback N, Hazlewood GS (2020) Patient preferences for disease-modifying antirheumatic drug treatment in rheumatoid arthritis: a systematic review. J Rheumatol 47(2):176-187. https://doi.org/10.3899/jrheum. 181165

10. Bywall KS, Kihlbom U, Hansson M, Falahee M, Raza K, Baecklund E, Veldwijk J (2020) Patient preferences on rheumatoid arthritis second-line treatment: a discrete choice experiment of Swedish patients. Arthritis Res Ther 22(1):288. https://doi.org/ 10.1186/s13075-020-02391-w

11. European Medicines Agency (2021) http://www.ema.europa.eu/ ema. Accesed June 2021

12. U.S. Department of Health and Human Services, Food and Drug Administration, Center for Devices and Radiological Health and Center for Biologics Evaluation and Research (2016) Patient preference information - voluntary submission, review in premarket approval applications, humanitarian device exemption applications, and de novo requests, and inclusion in decision summaries and device labeling. Guidance for Industry, Food and Drug Administration Staff, and Other Stakeholders. https://www.fda. gov/media/92593. Accesed June 2021

13. van den Heuvel L, Dorsey RR, Prainsack B, Post B, Stiggelbout AM, Meinders MJ, Bloem BR (2020) Quadruple decision making for parkinson's disease patients: combining expert opinion, patient preferences, scientific evidence, and big data approaches to reach precision medicine. J Parkinsons Dis 10(1):223-231. https://doi. org/10.3233/JPD-191712

14. Bridges JF, Hauber AB, Marshall D, Lloyd A, Prosser LA, Regier DA, Johnson FR, Mauskopf J (2011) Conjoint analysis applications in health - a checklist: a report of the ISPOR Good Research Practices for Conjoint Analysis Task Force. Value Health 14(4):403-413. https://doi.org/10.1016/j.jval.2010.11.013

15. Alten R, Kruger K, Rellecke J, Schiffner-Rohe J, Behmer O, Schiffhorst G, Nolting HD (2016) Examining patient preferences in the treatment of rheumatoid arthritis using a discrete-choice approach. Patient Prefer Adherence 10:2217-2228. https://doi.org/ 10.2147/PPA.S117774

16. Aletaha D, Neogi T, Silman AJ, Funovits J, Felson DT, Bingham CO 3rd, Birnbaum NS, Burmester GR, Bykerk VP, Cohen MD et al (2010) 2010 rheumatoid arthritis classification criteria: an American College of Rheumatology/European League Against Rheumatism collaborative initiative. Arthritis Rheum 62(9):2569 2581. https://doi.org/10.1002/art.27584

17. Augustovski F, Beratarrechea A, Irazola V, Rubinstein F, Tesolin P, Gonzalez J, Lencina V, Scolnik M, Waimann C, Navarta D et al (2013) Patient preferences for biologic agents in rheumatoid arthritis: a discrete-choice experiment. Value Health 16(2):385393. https://doi.org/10.1016/j.jval.2012.11.007

18. Harrison M, Marra C, Shojania K, Bansback N (2015) Societal preferences for rheumatoid arthritis treatments: evidence from a discrete choice experiment. Rheumatology (Oxford) 54(10):18161825. https://doi.org/10.1093/rheumatology/kev113

19. Bansback N, Harrison M, Marra C (2016) Does introducing imprecision around probabilities for benefit and harm influence the way people value treatments? Med Decis Making 36(4):490 502. https://doi.org/10.1177/0272989X15600708

20. Constantinescu F, Goucher S, Weinstein A, Fraenkel L (2009) Racial disparities in treatment preferences for rheumatoid arthritis. Med Care 47(3):350-355. https://doi.org/10.1097/MLR.0b013 e31818af829

21. Fraenkel L, Bogardus ST, Concato J, Felson DT, Wittink DR (2004) Patient preferences for treatment of rheumatoid arthritis. 
Ann Rheum Dis 63(11):1372-1378. https://doi.org/10.1136/ard. 2003.019422

22. Fraenkel L, Bogardus S, Concato J, Felson D (2002) Unwillingness of rheumatoid arthritis patients to risk adverse effects. Rheumatology (Oxford) 41(3):253-261. https://doi.org/10.1093/rheum atology/41.3.253

23. Hazlewood GS, Bombardier C, Tomlinson G, Thorne C, Bykerk VP, Thompson A, Tin D, Marshall DA (2016) Treatment preferences of patients with early rheumatoid arthritis: a discrete-choice experiment. Rheumatology (Oxford) 55(11):1959-1968. https:// doi.org/10.1093/rheumatology/kew280

24. Husni ME, Betts KA, Griffith J, Song Y, Ganguli A (2017) Benefit-risk trade-offs for treatment decisions in moderate-to-severe rheumatoid arthritis: focus on the patient perspective. Rheumatol Int 37(9):1423-1434. https://doi.org/10.1007/s00296-017-3760-z

25. Louder AM, Singh A, Saverno K, Cappelleri JC, Aten AJ, Koenig AS, Pasquale MK (2016) Patient preferences regarding rheumatoid arthritis therapies: a conjoint analysis. Am Health Drug Benefits 9(2):84-93

26. Poulos C, Hauber AB, Gonzalez JM, Turpcu A (2014) Patients' willingness to trade off between the duration and frequency of rheumatoid arthritis treatments. Arthritis Care Res 66(7):10081015. https://doi.org/10.1002/acr.22265

27. van der Elst K, Meyfroidt S, De Cock D, De Groef A, Binnard E, Moons P, Verschueren P, Westhovens R (2016) Unraveling patient-preferred health and treatment outcomes in early rheumatoid arthritis: a longitudinal qualitative study. Arthritis Care Res 68(9):1278-1287. https://doi.org/10.1002/acr.22824

28. van Tuyl LH, Sadlonova M, Hewlett S, Davis B, Flurey C, Goel N, Gossec L, Heegaard Brahe C, Hill CL, Hoogland W et al (2017) The patient perspective on absence of disease activity in rheumatoid arthritis: a survey to identify key domains of patientperceived remission. Ann Rheum Dis 76(5):855-861. https://doi. org/10.1136/annrheumdis-2016-209835

29. van Heuckelum M, Mathijssen EG, Vervloet M, Boonen A, Hebing RC, Pasma A, Vonkeman HE, Wenink MH, van den Bemt BJ, van Dijk L (2019) Preferences of patients with rheumatoid arthritis regarding disease-modifying antirheumatic drugs: a discrete choice experiment. Patient Prefer Adherence 13:1199-1211. https://doi.org/10.2147/PPA.S170721

30. Loyola-Sanchez A, Hazlewood G, Crowshoe L, Linkert T, Hull PM, Marshall D, Barnabe C (2020) Qualitative study of treatment preferences for rheumatoid arthritis and pharmacotherapy acceptance: indigenous patient perspectives. Arthritis Care Res 72(4):544-552. https://doi.org/10.1002/acr.23869

31. Scalone L, Sarzi-Puttini P, Sinigaglia L, Montecucco C, Giacomelli R, Lapadula G, Olivieri I, Giardino AM, Cortesi PA, Mantovani LG et al (2018) Patients', physicians', nurses', and pharmacists' preferences on the characteristics of biologic agents used in the treatment of rheumatic diseases. Patient Prefer Adherence 12:2153-2168. https://doi.org/10.2147/PPA.S168458

32. Fayad F, Ziade NR, Merheb G, Attoui S, Aiko A, Mroue K, Masri AF (2018) Patient preferences for rheumatoid arthritis treatments: results from the national cross-sectional LERACS study. Patient Prefer Adherence 12:1619-1625. https://doi.org/10.2147/PPA. S168738

33. Mathijssen EG, van Heuckelum M, van Dijk L, Vervloet M, Zonnenberg SM, Vriezekolk JE, van den Bemt BJ (2018) A discrete choice experiment on preferences of patients with rheumatoid arthritis regarding disease-modifying antirheumatic drugs: the identification, refinement, and selection of attributes and levels. Patient Prefer Adherence 12:1537-1555. https://doi.org/10.2147/ PPA.S170721

34. Wangdahl JM, Martensson LI (2015) Measuring health literacy - the Swedish Functional Health Literacy scale. Scand J Sci 29(1):165-172. https://doi.org/10.1111/scs.12125

35. Wangdahl JM, Martensson LI (2014) The communicative and critical health literacy scale-Swedish version. Scand J Public Health 42(1):25-31. https://doi.org/10.1177/1403494813500592

36. Gale NK, Heath G, Cameron E, Rashid S, Redwood S (2013) Using the framework method for the analysis of qualitative data in multi-disciplinary health research. BMC Med Res Methodol 13:117. https://doi.org/10.1186/1471-2288-13-117

37. Hazlewood GS (2018) Measuring patient preferences: an overview of methods with a focus on discrete choice experiments. Rheum Dis Clin North Am 44(2):337-347. https://doi.org/10.1016/j.rdc. 2018.01.009

38. Hsiao B, Fraenkel L (2019) Patient preferences for rheumatoid arthritis treatment. Curr Opin Rheumatol 31(3):256-263. https:// doi.org/10.1097/BOR.0000000000000591

Publisher's note Springer Nature remains neutral with regard to jurisdictional claims in published maps and institutional affiliations. 


\title{
Authors and Affiliations
}

\author{
Karin Schölin Bywall ${ }^{1}$ (D) Bente Appel Esbensen ${ }^{2,3} \cdot$ Marta Lason $^{4} \cdot$ Marie Heidenvall $^{5} \cdot$ Inger Erlandsson $^{5}$. \\ Jennifer Viberg Johansson ${ }^{1,6}$ \\ Bente Appel Esbensen \\ bente.appel.esbensen@ regionh.dk \\ Marta Lason \\ marta@elsa.science \\ Marie Heidenvall \\ marie.heidenvall@gmail.com \\ Inger Erlandsson \\ ingere.kalmar@gmail.com \\ Jennifer Viberg Johansson \\ 2 Copenhagen Center for Arthritis Research (COPECARE), \\ Center for Rheumatology and Spine Diseases, Centre \\ of Head and Orthopaedics, Rigshospitalet, Denmark \\ 3 Department of Clinical Medicine, Faculty of Health \\ and Medical Sciences, University of Copenhagen, \\ Copenhagen, Denmark \\ 4 Elsa Science, Stockholm, Sweden \\ 5 Rheumatism Association, Stockholm, Sweden \\ 6 Institute for Future Studies, Stockholm, Sweden
}

jennifer.viberg@crb.uu.se

1 Department of Public Health and Caring Sciences, Centre for Research Ethics \& Bioethics, Uppsala University,

Uppsala, Sweden 